\title{
EFEKTIVITAS PENDIDIKAN KESEHATAN GIGI DENGAN METODE DEMONSTRASI TERHADAP KEBERSIHAN GIGI DAN MULUT PADA PASIEN RAWAT INAP DI RUMAH SAKIT BHAYANGKARA TINGKAT III MANADO
}

\author{
I Ketut Harapan', Jean Henry Raule ${ }^{2}$ \\ 1,2) Jurusan Keperawatan Gigi Poltekkes Kemenkes Manado \\ Email : iketutharapan@gmail.com
}

\begin{abstract}
ABSTRAK
Latar Belakang : Pendidikan kesehatan merupakan suatu proses belajar mengajar pada individu atau kelompok masyarakat tentang nilai-nilai kesehatan sehingga mereka mampu mengatasi masalah kesehatan, Pengukuran indek kebersihan gigi dan mulut merupakan upaya untuk memantau keadaan kebersihan gigi dan mulut seseorang. Kesehatan gigi dan mulut penting bagi kesehatan dan kesejahteraan tubuh secara umum dan sangat mempengaruhi kualitas kehidupan, termasuk fungsi bicara, pengunyahan dan rasa percaya diri. Mengukur kebersihan gigi dan mulut merupakan upaya untuk menetukan keadaan kebersihan gigi dan mulut seseorang. Pada umumnya untuk mengukur kebersihan gigi dan mulut digunakan suatu index OHIS. Tujuan penelitian ini yaitu untuk mengetahui Efektivitas Pendidikan Kesehatan Gigi Dengan Metode Demonstrasi Terhadap Kebersihan Gigi dan Mulut pada pasien rawat inap di RS Bhayangkara TK III Manado. Metode : Jenis penelitian ini adalah penelitian kuantitatif yang menggunakan pendekatan Quasi Experiment dengan desain One Group Pretest-Posttest, yang bertujuan untuk melihat perbedaan OHI-S sebelum dan sesudah diberikan pendidikan kesehatan gigi dengan metode demonstrasi, tentang teknik meyikat gigi pada pasien rawat inap di RS Bhayangkara TK III Manado, dengan teknik accidental sampling pada 30 respondenyang menggunakan analisis statistik Wilcoxon. Hasil: Dari hasil uji ditemukan nilai signifikansi $p=0,000$ dimana nilai $p<0,05$ sehingga $\mathrm{H}_{0}$ ditolak $\mathrm{H}_{1}$ diterima bahawa ada perbedaan pendidikan kesehatan gigi dengan metode demonstrasi terhadap kebersihan gigi dan mulut pada pasien rawat inap di RS Bhayangkara TK III Manado.Kesimpulan : kesimpulan bahwa terdapat perbedaan nilai OHI-S sebelum dan sesudah diberikan pendidikan kesehatan gigi dengan metode demonstrasi pada pasien rawat inap di RS Bhayangkara TK III Manado dengan nilai signifikan yaitu $p=0,000(p<0,05)$.
\end{abstract}

\section{Kata Kunci : Pendidikan Kesehatan Gigi, Metode Demonstrasi, OHIS}

\begin{abstract}
Background: Health education is a learning-teaching process towards an individual or group of people about health value so that they could overcome health issue, oral hygiene index measurement is an effort to measure someone's oral hygiene. Oral health is important to overall health and wellbeing and affect a lot to life quality, including the function of speaking, mastication and confident. Measuring oral hygiene is an effort to establish someone's oral hygiene conditions.To measure oral hygiene, usually OHI-S index is used. The purpose of this study is to understand the effectivity of dental education using demonstration methods on oral hygiene of inpatient Bhayangkara $3^{\text {rd }}$ degree hospitals. Method : Type of observation in this study are kuatitatif research that uses quasi experimental with one group pretest-posttest, that aim to observe OHI-S difference before and after dental education is given out with demonstration methods, about tooth brushing technique on inpatient of Bhayangkara $3^{\text {rd }}$ degree hospitals, Manado; using accidental sampling technique on 30 respondent that uses Wilcoxon
\end{abstract}


statistic analysis. Result : From the test result significance $p$ value $p=0,000$ where value of $p<$ 0,05 ; so that $\mathrm{H}_{0}$ is rejected and $\mathrm{H}_{1}$ is accepted where there are difference of oral hygiene on inpatient of Bhayangkara $3^{\text {rd }}$ hospitals whose been educated with demonstration methods. Conclusion: There are OHI-S value difference before and after oral health education with demonstration methods is give to inpatient of Bhayangkara $3^{\text {rd }}$ degree hospitals, Manado; with significance value of $\mathrm{p}=0,000(\mathrm{p}<0,05)$.

\section{Key words: Oral Health Education, Demonstration methods, OHI-S}

\section{PENDAHULUAN}

Kesehatan adalah keadaan sehat, baik secara fisik, mental, spiritual maupun social yang memungkinkan setiap orang untuk hidup produktif secara social dan ekonomis. Upaya kesehatan setiap kegiatan dan/atau serangkaian kegiatan yang di lakukan secara terpadu, terintegrasi dan berkesinambungan untuk memelihara dan meningkatkan derajat kesehatan masyarakat dalam bentuk pencegahan penyakit, peningkatan kesehatan, pengobatan penyakit, dan pemulihan kesehatan oleh pemerintah dan/atau masyarakat $^{10}$.

Pendidikan kesehatan adalah suatu penerapan atau aplikasi konsep pendidikan dan konsep sehat. Adapun konsep pendidikan kesehatan adalah proses belajar mengajar pada individu atau kelompok masyarakat tentang nilai-nilai kesehatan sehingga mereka mampu mengatasi masalah kesehatan. Menurut Tiglao, pendidikan kesehatan "bukan sekedar" memberitahukan kepada orang-orang bagaimana caranya untuk mempertinggi kesempatan untuk belajar, dengan dan untuk mereka sendiri, akibatnya mereka dapat mengubah cara hidupnya yang kurang baik untuk kesehatan pribadinya dan untuk masyarakat ${ }^{6}$.

Kesehatan gigi dan mulut penting bagi kesehatan dan kesejahteraan tubuh secara umum dan sangat mempengaruhi kualitas kehidupan, termasuk fungsi bicara, pengunyahan dan rasa percaya diri.
Mengukur kebersihan gigi dan mulut merupakan upaya untuk menetukan keadaan kebersihan gigi dan mulut seseorang. Pada umumnya untuk mengukur kebersihan gigi dan mulut digunakan suatu index ${ }^{15}$.

Data riset kesehatan dasar (RISKESDAS) pada tahun 2013 prevalensi penduduk Indonesia yang bermasalah dengan kesehatan gigi dan mulut mencapai 25,9\%. di provinsi Sulawesi Utara persentase penduduk umur $\geq 10$ tahun menyikat gigi setiap hari dan berperilaku benar menyikat yaitu sebesar 95,3\% menyikat gigi pada saat mandi sore sedangkan $32,4 \%$ menyikat gigi pada malam sebelum tidur ${ }^{11}$.

Perawatan kebersihan gigi dan mulut merupakan bagian penting dari pengobatan untuk semua pasien. Menurut kamus besar Bahasa Indonesia, pasien rawat inap merupakan pasien yang dirawat dan menginap di rumah sakit. Pasien rawat inap akan cenderung mengalami masalah kesehatan dan kebersiahan mulut, di karenakan pengetahuan yang kurang dan ketidak mampuan untuk memepertahankan kebersihan oral, antara lain pasien yang mengalami penyakit serius, pasien yang kesadarannya menurun, dan pasien yang mengalami koma. Kebersihan mulut yang buruk pada pasien rawat inap jika tidak segera ditangani dapat menyebabkan timbulnya masalah baru, karena mulut merupakan bagian pertama saluran makanan dan system pernapasan ${ }^{7}$. 
Hasil peneitian yang dilakukan Indriastuti di RS Jiwa Surakarta, didapatkan hasil pengukuran indeks plak sebelum melakukan pendidikan kesehatan gigi yaitu sebesar 60,44 \%, sedangkan hasil pengukuran indeks plak sesudah melakukan pendidikan kesehatan gigi yaitu sebesar $27,55 \%$. hal ini menunjukkan bahwa pendidikan kesehatan gigi berpengaruh baik terhadap penurunan skor plak indeks pada pasien di Rumah Sakit Jiwa daerah Surakarta.

Penelitian yang serupa juga dilakukan Restuning dkk, di Puskemas Beber Kabupaten Cirebon, menunjukan adanya perbedaan yang bermakna rata-rata skor OHI-S awal dan akhir dilakukan asuhan keperawatan gigi pada pasien rawat inap ${ }^{17}$.

Berdasarkan data hasil survey awal yang dilakukan pada tanggal 17 April 2017 di ruang Interna Bedah yang merupakan ruang rawat inap pada pasien umum dengan banyak macam jenis penyakit di RS Bhayangkara TK III Manado, melalui wawancara dan pemeriksaan kepada pasien, diketahui bahwa pasien belum pernah mendapatkan pendidikan kesehatan gigi dan mulut oleh tenaga kesehatan, dan dari hasil pemeriksaan gigi dan mulut dari 16 pasien di dapatkan rata-rata OHIS yaitu 2,5 hal ini telah melebihi standar OHI-S yaitu 0 - 1,2 dengan katagori baik

Pendidikan kesehatan gigi adalah usaha terencana dan terarah untuk menciptakan suasana agar seseorang atau kelompok masyarakat mau mengubah perilaku lama yang kurang menguntungkan untuk kesehatan gigi, menjadi lebih untuk kesehatan giginya. Pendidikan kesehatan gigi merupakan salah satu program kesehatan gigi dengan tujuan menanggulangi masalah kesehatan gigi di Indonesia ${ }^{2}$.

Beberapa pendekatan metode dalam pendidikan kesehatan gigi salah satunya yaitu dengan cara demonstrasi. Demonstrasi adalah salah satu cara menyajikan informasi dengan cara mempertunjukkan secara langsung obyeknya atau menunjukkan suatu proses atau prosedur ${ }^{5}$.

Metode demonstrasi juga menyajian materi dengan cara memperlihatkan bagaimana melakukan suatu tindakan atau begaimana melaksanakan suatu prosedur. Biasanya didahului pembicaraan lisan dengan bantuan alat bantu seperti gambar, model, atau ilustrasi lainnya ${ }^{1}$.

Keuntungan menggunakan metode demonstrasi adalah proses penerimaan sasaran terhadap materi penyuluhan akan lebih berkesan secara mendalam, orang akan lebih percaya dengan materi yang diberikan, benda yang digunakan benar-benar nyata, peragaan dapat diulang dan dicoba oleh peserta, situasi penyuluhan dalam keadaan santai dan masalah atau pertanyaan yang ada dapat terjawab ${ }^{5}$. Keuntungannya dapat memberi kesempatan kepada peserta didik untuk lebih banyak menggunakan indranya di dalam mempersepsiakan materi sehingga mudah dicerna dan dapat menguji kepandaian dalam bentuk keterampilan ${ }^{1}$.

Pelaksanaan metode demonstrasi yaitu dengan menciptakan suasana akrab dengan menampilakan sikap yang ramah dan dapat dipercaya,menjelaskan materi dengan menggunakan media dan yang akan didemonstrasikan, memperkenalkan nama dan bagian-bagian penting dengan cara mengulang-ulang, memberikan kesempatan menjawab pertanyaan dan mengulang apa yang telah diinformasikan ${ }^{5}$.

Menyikat gigi adalah cara yang umum dianjurkan untuk membersihkan deposit lunak yang menempel pada permukaan gigi dan gusi dan merupakan tindakan preventif dalam menuju kebersihan gigi dan kesehatan rongga mulut yang ${ }^{15}$. 
Pada umumnya untuk mengukur kebersihan gigi dan mulut digunakan suatu indeks. indeks adalah suatu angka yang menujukan keadaan klinis yang didapat pada waktu dilakukan pemeriksaan dengan cara mengukur luas dari permukaan gigi yang ditutupi oleh plak maupun kalkulus, jika kita sudah mengetahui nilai atau angka kebersihan gigi dari seorang pasien, kita dapat memberikan pendidikan dan penyuluhan,motivasi dan evaluasi, yaitu dengan melihat kemajuan ataupun kemuduran kebersihan gigi dan mulut seseorang atau sekelompok orang ataupun kita dapat melihat pebedaan klinis sesorang atau sekelompok orang ${ }^{15}$.

Untuk mengukur kebersihan gigi dan mulut, Green and Vermillion menggunakan indeks yang dikenal dengan Simplified Oral Hygiene Indeks (OHI-S). Green and Vermillion. menetukan enam permukaan gigi pilihan yang dapat mewakili semua segmen anterior dan posterior mulut berdasarkan pemeriksaan yang dilakukan pada seluruh mulut. gigi - gigi yang dipilih sebagi gigi indeks beserta permukaan indeks yang dianggap mewakili tiap segmen adalah: gigi 16 pada permukaan bukal, gigi 11 pada permukaan labial, gigi 26 pada permukaan bukal, gigi 36 pada permukaan lingual, gigi 31 pada permukaan labial dan gigi 46 pada permukaan lingual.permukaan yang diperiksa adalah permukaan gigi yang jelas terlihat dalam mulut, yaitu permukaan klinis bukan permukaan anatomis ${ }^{15}$.

Tujuan dari penelitian ini adalah untuk mengetahui efektivitas pendidikan kesehatan gigi dengan metode demonstrasi terhadap kebersihan gigi dan mulut pada pasien rawat inap di RS Bhayangkara TK III Manado.

Hasil dari penelitian ini diharapkan dapat memberikan manfaat dan masukan di bidang kesehatan gigi dan mulut yang berkaitan dengan efektivitas pendidikan kesehatan gigi dengan metode demonstasi terhadap kebersihan gigi dan mulut pada pasien rawat inap di RS Bhayangkara TK III Manado.

\section{METODE PENELITIAN}

Jenis penelitian digunakan ini yaitu penelitian kuantitatif yang mengguanakan pendekatan Quasi Eksperiment dengan desain "One Group Pretest-PostTest" rancangan ini tidak ada kelompok kontrol.

\begin{tabular}{ccc}
\hline Pre test & Perlakuan & Post test \\
\hline 01 & $\mathrm{X}$ & 02 \\
\hline
\end{tabular}

Penelitian ini dilakukan pada bulan Mei minggu ke empat 2017, dan lokasi penelitian yaitu di ruang Interna Bedah pada RS Bhayangkara TK III Manado

Variabel penelitian yaitu variable bebas : PendidikanKesehatan Gigidengan Metode Demonstrasi, dan variabel terikat : Kebersihan Gigi dan Mulut pada pasien rawat inap.

\section{Definisi Operasional}

1. Pendidikan kesehatan gigi adalah kegiatan penyuluhan yang dilakukan untuk memberikan informasi kepada pasien mengenai kesehatan gigi dan mulut tentang menyikat gigi dengan menggunakan metode demonstrasi pada pasien rawat inap yang berada di ruang Interna Bedah yang merupakan ruang rawat inap pasien umum dengan banyak macam jenis penyakit yang diderita.

2. Metode demonstrasi adalah suatu cara penyajian informasi dengan cara mempertunjukkan secara langsung objeknya atau suatu proses atau prosedur, metode tersebut sangat baik digunakan dengan materi penyuluhan menyikat gigi dengan menggunakan alat peraga yaitu phantom rahang orang dewasa dan sikat gigi. 
3. Kebersihan gigi dan mulut adalah upaya untuk menentukan kebersihan gigi dan mulut sesorang. Pemeriksaan OHI-S menggunakan instrument diagnose set, cara pengukuran menggunakan index OHI-S oleh Green and Vermillion, dengan menggunakan skalaordinal kriteria penilaian OHI-S baik yaitu 3, sedang 2 dan buruk 1 .

4. Pasien rawat inap adalah pasien yang dirawat dan menginap di rumah sakit. Pasien rawat inap yang dijadikan sampel adalah pasien yang berada di dalam ruangan interna bedah dengan kriteria pasien dalam keadaan sadar, pasien yang tidak sakit parah, pasien yang dapat melakukan aktifitas, pasein tidak dalam keadaan istrahat total dan pasien yang bersedia menjadi responden.

Populasi dalam penelitian ini yaitu pasien rawat inap ruang interna bedah di RS Bhayangkara TK III Manado berjumlah 40 orang, dan Sampel dalam penelitian ini adalah pasien rawat inap yang berada di ruangan Interna Bedah yang berjumlah 30 pasien, yang diambil dalam pengambilan sampel yaitu accidental sampling dengann kriteria inklusi sebagai berikut : 1) pasien rawat inap dengan keadaan sadar, 2) pasien rawat inap tidak dalam keadaan sakit yang parah, 3) pasien rawat inap yang masih dapat melakukan aktivitas, 4) pasien yang tidak dalam istrahat total dan 5) pasien rawat inap yang bersedia dijadikan sampel.

Instrument penelitian terdiri dari: format pemeriksaan OHI-S dan diagnosa set serta bahan disclosing, kapas alkahol 70\%, dan Ner beken, tempat kapas dan alat diagnoset yang terdiri dari kaca mulut, sonde, pinset, dan excavator. Data yang diperoleh diolah menggunakan perangkat lunak computer dengan menggunakan uji Wilcoxon untuk mengetahui efektivitas pendidikan kesehatan gigi dengan metode demonstrasi terhadap kebersihan gigi dan mulut pada pasien rawat inap di RS Bhayangkara TK III Manado, kemudian data dianalisis menggunakan perangkat lunak komputer.

\section{HASIL DAN PEMBAHASAN \\ Hasil Penelitian}

Gambaran penelitian ini dilakukan pada pasien rawat inap ruangan interna bedah di RS Bhayangkara TK III Manado, berdirinya RS Bhayangkara TK III Manado berawal dari diresmikannya klinik bersalin Bhayangkari Manado pada tanggal 26 februari 1996 oleh Kolonel Drs. Bambang Hermawan selaku kapolda Sulut dan kemudian berkembang menjadi TPS (Tempat Perawatan Sementara) berdasarkan Skep Kapolri No.Pol. : Skep/ 1549/ X/2001. Tanggal 30 oktober 2001 menjadi RS Bhayangkara TK III Manado dan sudah terakreditasi 5 pelayanan dasar kemenkes tinggkat C Nomor : HK.02.03/1/0906/2014.

1. Gambaran hasil penelitian berdasarkan distribusi Responden menurut Jenis Kelamin

Distribusi responden berdasarkan jenis kelamin dapat dilihat pada tabel 1 .

Tabel 1. Distribusi Responden Berdasarkan Jenis Kelamin

\begin{tabular}{ccc}
\hline Jenis Kelamin & Jumlah & $\begin{array}{c}\text { Presentase } \\
(\%)\end{array}$ \\
\hline Perempuan & 15 & 50 \\
Laki-Laki & 15 & 50 \\
\hline Total & 30 & 100 \\
\hline
\end{tabular}

Berasarkan data pada tabel 1 menunjukkan bahwa distribusi responden menurut jenis kelamin yaitu laki-laki berjumlah 15 (50\%) responden, sedangkan perempuan berjumlah 15 ( 50\%) responden. 
2. Distribusi Responden Berdasarkan Kebersihan Gigi dan Mulut Sebelum dan Sesudah Pendidikan Kesehatan Gigi yaitu,

Tabel 2. Distribusi Kebersihan Gigi dan Mulut Responden Sebelum dan Sesudah Pendidikan Kesehatan Gigi

\begin{tabular}{|c|c|c|c|c|c|c|c|c|}
\hline \multirow{2}{*}{$\begin{array}{c}\text { Pend. } \\
\text { Kesehat } \\
\text { an Gigi }\end{array}$} & \multicolumn{6}{|c|}{ Kriteria OHI-S } & \multirow[t]{2}{*}{$\mathbf{N}$} & \multirow{2}{*}{$\begin{array}{c}\text { Presentase } \\
(\%)\end{array}$} \\
\hline & $\begin{array}{l}\text { Bai } \\
k\end{array}$ & $\%$ & $\begin{array}{c}\text { Sedan } \\
\text { g }\end{array}$ & $\%$ & Buruk & $\%$ & & \\
\hline Sebelum & 1 & 3,3 & 19 & 53,3 & 10 & $\begin{array}{r}33 \\
3\end{array}$ & 30 & 100 \\
\hline Sesudah & 8 & 26,6 & 22 & 3,3 & 0 & 0 & 30 & 100 \\
\hline
\end{tabular}

Berdasarkan tabel 2 menunjukkan bahwa kebersihan gigi dan mulut responden sebelum penyuluhan "Baik" sebanyak 1 (3,3\%) responden, dan "Sedang" sebanyak $19(63,3 \%)$ responden, dan "Buruk" sebanyak $10(33,3 \%)$ responden. Sedangkan kebersihan gigi dan mulut sesudah diberikan penyuluhan terdistribusi "Baik" sebanyak 8 $(26,6 \%)$ responden, dan "Sedang" sebanyak $22(73,3 \%)$ responden, dan "Buruk" tidak ada responden.

3. Distribusi responden berdasarkan nilai rata - rata OHI-S sebelum dan sesudah pendidikan kesehatan gigi dengan metode demonstrasi dapat dilihat pada tabel 3 .

Tabel 3. Distribusi nilai rata-rata $\mathrm{OHI}-\mathrm{S}$ Sebelum dan sesudah pendidikan kesehatan gigi dengan metode demonstrasi

\begin{tabular}{cc}
\hline Nilai OHI-S & Nilai Rata-rata OHI-S \\
\hline Sebelum & 2,69 \\
Sesudah & 1,79 \\
\hline
\end{tabular}

Berdasarkan tabel 3 menunjukkan bahwa nilai rata-rata $\mathrm{OHI}-\mathrm{S}$ sebelum diberikan pendidikan kesehatan gigi dengan metode demonstrasi yaitu 2,69. Sedangkan sesudah diberikan pendidikan kesehatan gigi dengan metode demonstrasi yaitu 1,79 .

4. Hasil analisa statistik perbedaan nilai OHII-S sebelum dan sesudah diberikan pendidikan kesehatan gigi dengan menggunakan Wilcoxon pada tabel 4 Tabel 4. Hasil Analisa Uji Wilcoxon

\begin{tabular}{llcl}
\hline & $\mathrm{N}$ & $\begin{array}{c}\text { Median } \\
\text { (Minimum- } \\
\text { Maksimum) }\end{array}$ & $p$ \\
\hline $\begin{array}{l}\text { Sebelum Pendidikan } \\
\text { Kesehatan Gigi }\end{array}$ & 30 & $2,69(1,2-4,5)$ & 0,000 \\
$\begin{array}{l}\text { Sesudah Pendidikan } \\
\text { Kesehatan Gigi }\end{array}$ & 30 & $1,79(0,8-3,0)$ & \\
\hline
\end{tabular}

Uji Wilcoxon, nilai $p<0,05$ : bermakna

Data pada tabel 4 menunjukkan bahwa terdapat perbedaan nilai OHI-S sebelum dan sesudah diberikan pendidikan kesehatan gigi, data tersebut dapat dilihat dari hasil uji statistik dengan nilai OHI-S sebelum diberikan pendidikan kesehatan gigi dengan nilai median 2,69 dari nilai minimum 1,2 dan nilai maksimum 4,5. sedangkan nilai OHI-S sesudah diberikan pendidikan kesehatan gigi dengan nilai median 1,79 dari nilai minimum 0,8 dan nilai maksimum 3,0. hal ini juga dapat di buktikan dengan perbedaan nilai signikansi yaitu $p=0,000(p<0,05)$.

\section{Pembahasan}

Pendidikan kesehatan gigi adalah usaha terencana dan terarah untuk menciptakan suasana agar seseorang atau kelompok masyarakat mau mengubah perilaku lama yang kurang menguntungkan untuk kesehatan gigi, menjadi lebih untuk kesehatan giginya. Pendidikan kesehatan gigi merupakan salah satu program kesehatan gigi dengan tujuan menanggulangi masalah kesehatan gigi di Indonesia ${ }^{2}$. 
Dalam pendidikan kesehatan gigi, banyak metode yang digunakan salah satunya yaitu metode dengan cara demonstrasi. Metode demonstrasi adalah suatu cara penyajian informasi dengan cara mempertunjukan secara langsung objeknya atau suatu proses atau prosedur. Selain itu, pendidikan kesehatan gigi dengan metode demonstrasi, pasien dapat melihat dan mempraktekkan langsung atau secara nyata bagaimana teknik menyikat gigi yang baik dan benar, sehingga diharapakan, akan terjadi perubahan kebersihan gigi dan mulut dalam konteks ini adalah perubahan nilai $\mathrm{OHI}-\mathrm{S}$ pada pasien rawat inap.

Hasil penelitian menunjukkan bahwa kebersihan gigi dan mulut responden sebelum penyuluhan katagori "Baik" sebanyak 1 (3,3\%) responden, dan "Sedang" sebanyak $19(63,3 \%)$ responden, dan "Buruk" sebanyak 10 (33,3\%) responden. Sedangkan kebersihan gigi dan mulut sesudah diberikan penyuluhan terdistribusi "Baik" sebanyak $8(26,6 \%)$ responden, dan "Sedang" sebanyak $22(73,3 \%)$ responden, dan "Buruk" tidak ada responden. Pada data tersebut menunjukkan bahwa kriteria OHI-S yang paling tinggi sebelum diberikan pendidikan kesehatan gigi yaitu kriteria sedang yang berjumlah 19 (63,3\%) responden, dan kriteria OHI-S yang paling tinggi setelah diberikan pendidikan kesehatan gigi yaitu kriteria sedang yang berjumlah 22 $(73,3 \%)$ responden. Setelah diberikan pengetahuan tentang teknik menyikat gigi, secara otomatis perilaku pasien akan berubah karena pasien telah mengetahui bangaimana cara memelihara kesehatan gigi dan mulut yaitu dengan sering menggosok gigi.

Berdasarkan hasil tabel 3 menunjukan bahwa nilai rata-rata OHI-S sebelum diberikan pendidikan kesehatan gigi dengan metode demonstrasi yaitu 2,69. Sedangkan nilai rata-rata OHI-S sesudah diberikan pendidikan kesehatan gigi dengan metode demonstrasi yaitu 1,79. Hal ini menunjukkan bahwa terjadi perubahan perilaku yang baik melalui pengetahuan tentang teknik menyikat gigi pada pasien rawat inap.

Menurut Notoadmojo (2003) perubahan perilaku terutama pada orang dewasa dimulai pada domain kognitif, dalam arti subjek tahu dahulu terhadap stimulus yang berupa materi atau objek di luarnya. timbulnya pengetahuan baru pada subjek tersebut, dan selanjutnya menimbulkan respons batin dalam bentuk sikap si subjek terhadap objek yang diketahui itu. Akhirnya rangsangan yakni objek telah diketahui dan disadari sepenuhnya tersebut akan menimbulkan respons lebih jauh lagi, yaitu berupa tindakan (action) terhadap atau sehubungan dengan stimulus atau objek tadi. $^{13}$

Berdasarkan analisa data pada tabel 4 dari hasil penelitian terdapat perbedaan antara nilai OHI-S sebelum dan sesudah diberikan pendidikan kesehatan gigi dengan metode demonstrasi yaitu dengan nilai signifikan $p=0,000 \quad(p<0,05)$. Dengan demikian maka $\mathrm{H}_{1}$ dapat diterima, yang artinya ada perbedaan pendidikan kesehatan gigi dengan metode demonstrasi terhadap kebersihan gigi dan mulut.

Penelitian ini sejalan sesuai dengan penelitian yang dilakukan oleh ${ }^{17}$, di Puskesmas Beber Kabupaten Cirebon, dengan hasil analisis diperoleh nilai signifikan yaitu $p=0,001$, artinya ada perbedaan yang bermakna skor OHI-S awal dan akhir pada pasien rawat inap yang dilakukan intervensi oral hygiene.

Penelitian ini juga sejalan sesuai dengan penelitian yang dilakukan ${ }^{18}$, yaitu menunjukkan adanya perbedaan yang bermakna perubahan tingkat pengetahuan sebelum dan sesudah pada kelompok responden yang diberi perlakuan pendidikan kesehatan gigi dengan metode demonstrasi, 
yaitu dengan $p=0,000$ adalah nilai signifikan. Hasil ini menunjukkan bahwa pendidikan kesehatan gigi dengan menggunakan metode demonstrasi sangat berpengaruh pada kebersihan gigi dan mulut pada pasien rawat inap, karena metode demonstrasi memiliki kelebihan proses penerimaan sasaran terhadap materi penyuluhan yang akan lebih berkesan secara mendalam sehingga membentuk pengertian dengan baik dan sempurna.

Keuntungan menggunakan metode demonstrasi adalah proses penerimaan sasaran terhadap materi penyuluhan akan lebih berkesan secara mendalam, orang akan lebih percaya dengan materi yang diberikan, benda yang digunakan benar-benar nyata, peragaan dapat diulang dan dicoba oleh peserta, situasi penyuluhan dalam keadaan santai dan masalah atau pertanyaan yang ada dapat terjawab ${ }^{5}$.

\section{Kesimpulan}

Berdasarkan hasil penelitian dan pembahasan diatas maka penulis menyimpulkan bahwa terdapat perbedaan nilai OHI-S sebelum dan sesudah diberikan pendidikan kesehatan gigi dengan metode demonstrasi pada pasien rawat inap di RS Bhayangkara TK III Manado dengan nilai signifikan yaitu $p=$ $0,000(p<0,05)$.

\section{Saran}

Setelah melaksanakan penelitian dan pembahasan hasil penelitian, maka peneliti dapat memberikan saran yaitu:

1. Bagi rumah sakit, disarankan untuk pasien rawat inap sebaikanya diberikan pendidikan kesehatan gigi dengan metode demonstrasi agar kesehatan gigi dan mulut pasien rawat inap tetap terjaga. karena dana langsung materi yang diberikan oleh petugas kesehatan.

2. Bagi pasien, diharapakan untuk tetap menjaga kebersihan gigi dan mulutnya dengan cara sering menggosok gigi walaupun dalam keadaan sakit agar tidak dapat menimbulakan penyakit yang baru.

\section{Daftar Pustaka}

1. Astoeti, T, E, (2006), Total Quality

Management dalam Pendidikan

Kesehatan Gigi di Sekolah, PT Raja

Grafindo Persada, Jakarta.

2.Budiharto, (2009),Pengantar Ilmu Perilaku

Kesehatan Gigi dan Pendidikan

Kesehatan Gigi , EGC, Jakarta.

3.Departemen Pendidkan dan Kebudayaan, (1996), Kamus Besar Bahasa Indonesia edisi II, Balai Pustaka.

4.Drg. Donna Pratiwi, Sp. Prosto, (2009). Gigi Sehat dan Cantik, PT Kompas Media Nusantara, Jakarta.

5.Herijulianti,E ,Indriani, T,S , \& Artini, S. (2002). Pendidikan Kesehatan Gigi, EGC,Jakarta.

6.Hidayat, R. Tandiari, A. (2016). Kesehatan

Gigi dan Mulut-Apa yang Sebaiknya Anda Tahu. CV ANDI OFFSET. Yogyakarta.

7.Isro'in, L, \& Andarmoyo S, (2012),Personal

Hygiene:Konsep,Proses danAplikasi dalam Praktik Keperawatan,Graha Ilmu, Yogyakarta.

8.Indriastuti L, (2015) Pengaruh Pendidikan Kesehatan Gigi (DHE) Tehadap Indeks Plak Penderita Schizophernia di Rumah Sakit Jiwa Daerah Surakarta, Surakarta. E-Jurnal

9.Karmawati, A, \& Yulita, I, Re,P, Rr, (2014). Konsep Dasar Pelayanan Asuhan Keperawatan Gigi Dan

Mulut, Yogyakarta

10.Kementerian Kesehatan RI, (2012). UUD RI Nomor 36 Tahun 2009, Tentang Kesehatan. 
11.Kementerian Kesehatan RI (2013). Riset

Kesehatan Dasar,Badan Penelitian dan Pengembangan Tenaga

Kesehatan, Kemenkes,Jakarta.

12.Notoadmojo, S, (2010). Metodologi Penelitian Kesehatan, PT. Rineka Cipta, Jakarta.

13.Notoadmojo, S, (2003). Ilmu Kesehatan Masyarakat, PT. Rineka Cipta, Jakarta.

14.Peraturan Menteri Kesehatan

RI,(2016).NO 20 Tahun 2016, Izin Penyelenggaraan Praktik Terapis Gigi dan Mulut, Biro Hukum dan Organisasi Sekretariat Jendral Kementerian Kesehatan, Jakarta.

15.Putri,M,H, Herijulianti, E, \& Nurjannah,N (2010) Ilmu Pencegahan Penyakit JaringanKeras dan Jaringan Pendukung Gigi,EGC,Jakarta.

16.Riwidikdo,H, (2009),Statistik Kesehatan,Mitra Cendekia, Yogyakarta.

17.Restuning, S, Setiawan, H, \& Hendari, R, (2014)Asuhan Keperawatn Gigi Dalam Melakukan Oral Hygiene pada Pasien Rawat Inap di Puskesmas Beber Kabupaten Cirebon, Semarang. E-Jurnal.

18.Santoso B, Sutomo B, Prasko, (2016) Penyuluhan Metode Audio Visual Dan Demonstrasi Terhadap Pengetahuan Menyikat Gigi Pada Anak Sekolah di SDN 02 Pedalangan, Semarang. Jurnal Kesehatan . 